\title{
Pulmonary tuberculosis in sarcoidosis patients: two cases
}

\author{
Fatma ÜÇSULAR ${ }^{1}$ \\ Gülistan KARADENIZ ${ }^{1}$ \\ Gülru POLAT ${ }^{1}$ \\ Enver YALNIZ ${ }^{1}$
}

\author{
${ }^{1}$ Dr. Suat Seren Göğüs Hastalıkları ve Göğüs Cerrahisi Eğitim ve Araştırma \\ Hastanesi, İzmir, Türkiye \\ ${ }^{1}$ Dr. Suat Seren Chest Diseases and Chest Surgery Training and Research \\ Hospital, Izmir, Turkey
}

To the Editor,

We thank Dr. Miyazaki et al. for their interest to our article entitled 'Pulmonary tuberculosis developed in sarcoidosis patients'. We also found it interesting to have tuberculosis in two patients with sarcoidosis who were referred to us for radiological progression. We wanted to present these two cases to draw attention to the development of tuberculosis in sarcoidosis patients in the light of literature. We could not benefit from literature which were cited by you, due to they were in Japanese. Your first question was 'Should we consider sarcoidosis as a risk of developing tuberculosis? Tuberculosis is difficult to distinguish with sarcoidosis and can mimic each other clinically and histopathologically. For this reason, mycobacteria have been implicated in the etiology of sarcoidosis (1). It is very important to distinguish, because their treatment is completely different. Although the presence of caseinous necrosis in granulomatous inflammation supports tuberculosis, the presence and/or production of Mycobacterium tuberculosis bacilli proves tuberculosis infection. In both of our cases tuberculosis cultures were negative at the time of diagnosis for Sarcoidosis, one of these patients was developed tuberculosis after the six-years and the other one was developed after the 20 years of the diagnosis of Sarcoidosis. In our interstitial lung diseases clinic, between the years of 2013 and 2018, 370 patients with histopathologically diagnosis with sarcoidosis, of which only two patients developed tuberculosis $(0.5 \%)$. Together with diabetes and hyperglycemia, these two cases received immunosuppressive treatment. Therefore, we think that immunosuppressive treatment rather than sarcoidosis poses a greater risk of tuberculosis development $(2,3)$. The other issue that the authors were interested is that absence of cavitary lesion. In our two patients, there was no cavitary lesion, but the patients who were referred to us with suspicion of sarcoidosis progression due to the development of new radiological findings such as atelectasis, consolidation and acinar micronodular infiltrates in the bilateral upper and middle lobes. In the first case, bilateral hilar and mediastinal lymphadenopathies, consolidation and atelectasis findings and in the second case, bilateral hilar and mediastinal lymphadenopathies, consolidation and atelectasis and also acinar micronodular infiltrations which were typical for tuberculosis were observed. The absence of cavitary lesion does not rule out tuberculosis, but existing these radiological findings can be seen in tuberculosis patients. In addition, atypical radiological presentations are expected in immunocompromised patients (4).

Consequently; in the presence of immunosuppressive conditions such as corticosteroid therapy and diabetes, tuberculosis should be kept in mind in sarcoidosis patients who have progression of radiological findings. If tuberculosis is suspected, microbiological examinations should be repeated. We would like to draw attention to development of tuberculosis in sarcoidosis patients who takes immunosuppresive therapy, radiological progression shouldn't be thought as progression of sarcoidosis, it might be the new condition.

\section{REFERENCES}

1. Maertzdorf J, Weiner J $3^{\text {rd }}$, Mollenkopf HJ, et al. Common patterns and disease-related signatures in tuberculosis and sarcoidosis. Proc Natl Acad Sci USA 2012;109:7853-8.

2. Al-Rifai RH, Pearson F, Critchley IA, Abu-Raddad LJ. Association between diabetes mellitus and active tuberculosis: a systematic review and meta-analysis. PLoS One 2017.

3. Yamagishi F. Medical risk factors of tuberculosis and countermeasures. Kekkaku 2002.

4. Geng E, Kreiswirth B, Burzynski J, Schluger NW. Clinical and radiographic correlates of primary and reactivation tuberculosis. JAMA 2005;293:2740-5.

\section{Yazışma Adresi (Address for Correspondence)}

Dr. Gülistan KARADENIZ

Dr. Suat Seren Göğüs Hastalıkları ve Göğüs Cerrahisi Eğitim ve Araştırma Hastanesi, IZMIR - TÜRKIYE

e-mail: drglstn35@gmail.com 